\title{
Patentes y desenvolvimiento tecnológico en México: un estudio comparativo entre la época de industrialización proteccionista y el régimen de apertura
}

\section{Patents and Technological Development in Mexico: A Comparative Study between the Era of Protectionist Industrialization and the Regime of Openness}

\author{
Juan I. Campa \\ Universidad Autónoma de Barcelona, Barcelona, España \\ xuan.ijnazio@gmail.com
}

\begin{abstract}
Resumen. El presente trabajo caracteriza y evalúa el comportamiento de la actividad de patentamiento en México durante el régimen de proteccionismo industrial de 1940 a 1970 y el régimen de liberalización económica entre 1995 y 2015. Para llevar a cabo el contraste entre etapas los datos de patentes se agrupan por sectores tecnológicos siguiendo la Clasificación Internacional de Patentes (CIP), lo que permite realizar análisis consistentes de manera temporal o espacial. La comparación de la evolución y estructuras del patentamiento entre periodos sugiere, en el ámbito de agregación expuesto, una continuidad en la dirección de la propensión a patentar por parte tanto de los titulares residentes como de los no residentes en los campos tecnológicos determinados. Esto muestra que el desarrollo tecnológico del país ha mantenido un mismo patrón durante ambos regímenes económicos.
\end{abstract}

Palabras clave: innovación; desarrollo tecnológico; patentes; propensión a patentar.

Abstract. The present work characterizes and evaluates the behavior of patenting activity in Mexico during the industrial protectionist regime of 1940 to 1970 and the economic liberalization regime between 1995 and 2015. In order to carry out a contrasting analysis between periods patent data are grouped by technological sectors according to the International Patent Classification (IPC), which allows for consistent analyzes in a temporal or spatial manner. The comparison of the evolution and structures of patenting between periods suggests, in the aggregation area exposed, a continuity in the direction of the propensity to patent both resident and non-resident holders in the determined technological fields. This shows that the technological development of the country has maintained the same pattern during both economic regimes.

Key words: innovation; technological development; intellectual property; propensity to patent.

Am. Lat. Hist. Econ., sept.-dic., 2018, pp. 223-257 | DOI: 10.18232/alhe.879 
JEL: O31; O33; O34; O35.

Fecha de recepción: 5 de abril de 2017. Fecha de aceptación: 2 de agosto de 2017.

\section{INTRODUCCIÓN}

$\mathrm{D}$ urante el régimen de industrialización por sustitución de importaciones (ISI en adelante) comprendido durante tres décadas, entre 1940 y 1970, México se modernizó económicamente en una dimensión no vista en etapas previas. Se alteraron las estructuras productivas en prácticamente todos los sectores de actividad y se registró una expansión y diversificación significativa en el sector manufacturero en particular, si bien se desarrolló en fases o subperiodos con características comunes y diferenciadas. Esto implicó que los cambios en las estructuras productivas también pasaran por un proceso significativo de modernización e innovación tecnológica. Debido a rigideces y agotamiento eventual del modelo de ISI, en parte por el sobreendeudamiento financiero externo y presiones fiscales, las crisis recurrentes y el fenómeno de la integración o globalización creciente experimentados en la década de los ochenta, el gobierno mexicano impulsó una serie de reformas dirigidas a la apertura de los mercados, la privatización de bienes públicos y la desreglamentación de las actividades económicas. Por consiguiente, a partir del establecimiento del Tratado de Libre Comercio de América del Norte (TLCAN) se erigió formalmente un modelo económico nuevo o de intercambio liberalizado entre 1995 y 2015 con políticas e incentivos diferenciados respecto del régimen precedente, aunque también con fases, ajustes y matices a lo largo del periodo. Esto condujo de igual modo a un proceso de reconversión industrial y con ello a un recambio tecnológico. ${ }^{1}$

En este artículo se examina el desenvolvimiento de las actividades tecnológicas en México presentando la estructura y evolución de las patentes que se concedieron durante ambos regímenes económicos. Por medio de la actividad de patentamiento podemos, en parte, caracterizar y conocer el ritmo, dirección o tendencia de las tecnologías novedosas que se protegieron dentro del territorio nacional y con ello trazar un perfil aproximado del tipo de cambio tecnológico experimentado en los dos regímenes económicos. Además, puesto que la inversión en la definición y protec-

\footnotetext{
${ }^{1}$ Sobre el desempeño de la economía mexicana, a lo largo de los dos periodos, véanse Cárdenas (2015), Márquez (2014), Kuntz (2010) o Moreno y Ros (2009). Para un contraste con experiencias de otros países latinoamericanos, véanse Bértola y Ocampo (2010), Cárdenas, Ocampo y Thorp (2003) o Fajnzylber (1983).
} 
ción de derechos de propiedad en general y de la intelectual en particular significa un esfuerzo importante para los innovadores, la trayectoria del patentamiento y su comparación entre los dos regímenes económicos nos permiten bosquejar los intereses de estos agentes, su continuidad o cambio ante los cambios de modelo económico y trazar plausiblemente o no una dependencia del camino recorrido o path dependency. El trabajo se enfoca en un análisis cuantitativo de la actividad de patentamiento al utilizar las referencias de los datos de patentes y no los textos de patentes en sí, por lo cual no se hace una aproximación cualitativa en el estudio a la manera de Bazerman (2002) o Bowker (1994).

La actividad de patentamiento como indicador de cambio tecnológico y económico ha sido un tema estudiado en diversos aspectos de manera relativamente amplia para países desarrollados (Sáiz, 2002). Por el contrario, son escasas las investigaciones que se han realizado sobre dicho tema en países en desarrollo. Este aspecto es esencial para poder entender y dimensionar la importancia y efectos que tiene para este último tipo de naciones. ${ }^{2}$ México se encuentra en esta situación. Si bien ya se han explorado ciertos aspectos del desenvolvimiento tecnológico nacional, todavía diversos temas permanecen sin desarrollar o se han examinado poco en el ámbito de la actividad de patentamiento. En términos generales, la literatura que ha abordado el estudio del cambio técnico mexicano se ha enfocado en presentar una cronología de acontecimientos sobre invenciones, políticas u organizaciones; definir o discutir los cortes o fases históricas del desarrollo tecnológico nacional; describir el origen y evolución de la política tecnológica formalmente establecida; discutir la adopción de tecnologías emulando valores o la cultura de las elites y clases medias extranjeras; formular proposiciones sobre el rumbo del desarrollo tecnológico que ha estado gobernado por la lógica de captura de rentas por parte de los empresarios e innovadores nacionales y extranjeros; o estudiar experiencias dinámicas en innovación en contextos específicos para regiones territoriales, industrias o empresas (Concha y Calleros, 1996; Corona, 2004; Gauss, 2011; Instituto Nacional de la Investigación Científica, 1970; Jeannot, 2001; Lomnitz y Pérez-Lizaur, 1987; María y Campos, 1968; Mercado, 1986; Padua, 1984; Pérez, 1996; Pérez-Lizaur, 1996; Rossi, 1977; Science and Technology Policy Instruments, 1980; Wionczek, 1981; Wionczek, Bueno y Navarrete, 1988). Sin embargo, buena parte de los trabajos se presentan de modo limitado o carecen en todo caso de una cuantificación sistemática o uniforme del desarrollo tecnológico y su desenvolvimiento a lo largo del horizonte temporal, en particular sin incluir información o con escasas

${ }^{2}$ Penrose (1974) es pionera en presentar una clara discusión sobre las ventajas y desventajas del régimen internacional de patentes para ambos tipos de países, desarrollados y en desarrollo. 
referencias sobre magnitudes relativas a la actividad del patentamiento nacional.

En general en contextos de países en desarrollo, como es el caso de México, el conjunto de las investigaciones de la actividad de patentamiento básicamente ha configurado dos argumentos. Uno se orienta esencialmente a la discusión de la participación de la política tecnológica nacional, en particular la del régimen de patentes que comprende tanto las legislaciones como el funcionamiento de las organizaciones administrativas y jurisdiccionales, y sus objetivos de fomento al desarrollo de capacidades tecnológicas locales o de incentivo a la inversión de adelantos tecnológicos provenientes del exterior. En general la conclusión es que la política de patentes establecida en países en desarrollo contribuye en poco al desarrollo de capacidades tecnológicas locales y favorece los intereses del patentamiento del exterior (ONU, 1964, 1975). El otro argumento, que se relaciona estrechamente con el anterior, formula que se ha configurado una dependencia tecnológica por medio del predominio del registro de patentes extranjeras en el patentamiento nacional, el cual se ha asentado como un rasgo característico de la evolución del desarrollo tecnológico de los países rezagados tecnológicamente (Katz, 1972; ONU, 1964, 1975; Vaitsos, 1972).

México, como país en desarrollo que ha buscado incentivar su progreso tecnológico, se ha enfrentado a la disyuntiva de estimular las capacidades inventivas locales como fuente de desarrollo de nuevas tecnologías o bien impulsar y aprovechar la transferencia de tecnología como el camino principal para el progreso material innovador. La literatura disponible sugiere que la política de patentes establecida en México en etapas históricas distintas se ha orientado a facilitar la atracción de tecnologías novedosas del exterior, aunque sin poder determinar su utilidad para promover la explotación efectiva de las patentes (Aboites, 1995; Aboites y Soria, 1999, 2008; Beatty, 2001, 2002, 2015; Campa, 2016). De esta manera, en la actividad de patentamiento nacional ha prevalecido la titularidad de las patentes de extranjeros o no residentes, en particular de las corporaciones transnacionales. La dependencia tecnológica del patentamiento del exterior en parte ha sido resultado de los incentivos conformados con la política de patentes; las oportunidades y expectativas de beneficios que ofrece la orientación de cada régimen económico prevaleciente; los modelos, las estructuras formales e informales y la organización que gobiernan la educación; el tipo de políticas de fomento a la creación y desarrollo de centros de investigación públicos y privados; el tipo de desarrollo institucional y los incentivos para la coordinación de los esfuerzos entre agentes y organismos públicos y privados, entre otros (Aboites y Soria, 2008, 1999; Beatty, 2015; Martínez, 2008). Sin embargo, uno de los elementos que 
faltan en la discusión es si el grado y dirección de la actividad de patentamiento, la propensión a patentar, y en especial la dependencia tecnológica de patentes extranjeras persisten o cambian cuando se transita de un tipo de régimen económico a otro. En particular, los estudios que han elaborado los autores previos no sugieren si el desenvolvimiento tecnológico del país, medido mediante la actividad de patentamiento, sigue un patrón recurrente o de persistencia de determinadas opciones tecnológicas o si refleja dinámicas de alteraciones significativas que indiquen una transformación efectiva del cambio tecnológico cuando se contrastan periodos diferentes de la historia económica mexicana.

Con base en lo anterior consideramos que el planteamiento que presentamos es novedoso y contribuye de manera original al estudio de diversos aspectos cruciales que tratan sobre el desarrollo tecnológico y económico de México. Puesto que ofrece evidencia nueva sobre la actividad de patentamiento durante el periodo de la ISI, propiciará que se exploren ideas y áreas de investigación más detalladas. La comparación entre dos periodos con regímenes económicos diferenciados no se ha expuesto en ningún otro trabajo que analice la actividad de patentamiento mexicana. Los trabajos de Aboites y Soria (1999 y 2008), por ejemplo, comprenden un periodo largo que abarca desde los años setenta del siglo pasado hasta la época actual. Sin embargo, el contraste pasa por un periodo de transición donde los incentivos de la ISI y del régimen liberal se entremezclaron durante las primeras dos décadas (1970 y 1980). En relación con lo anterior, en este artículo presentamos un perfil del desarrollo tecnológico agrupando los sectores tecnológicos siguiendo la Clasificación Internacional de Patentes (en adelante CIP), a diferencia de los autores mencionados que utilizan la clasificación tecnológica usada por la oficina de patentes estadunidense. Esto propicia que nuestros resultados sean más accesibles para hacer comparaciones posteriores con otros estudios de caso dado el empleo generalizado de la CIP. Además, en el análisis de la política de patentes los autores sólo exploran muy en lo general las características nominales de las legislaciones de patentes y sus cambios, pero ponen poco énfasis en identificar cómo ha operado o funcionado en la práctica el régimen de patentes mexicano. En este sentido, apuntamos a identificar y revisar con un cierto detalle tales aspectos. Por consiguiente, consideramos que el artículo hace una contribución importante al expandir el estudio de la historia de la tecnología y de la política tecnológica en el país en dos modelos económicos distintos mediante evidencia nueva de la actividad de patentamiento.

Sugerimos que el desarrollo tecnológico registrado por medio del registro de patentes durante el régimen económico de la ISI muestra similitudes con el vigente durante el intercambio liberalizado. Esto conlleva 
la proposición de que el perfil tecnológico nacional es dependiente de la trayectoria, aunque haya comprendido especificidades de continuidad y cambio. El concepto de dependencia de la trayectoria es diferente de la noción de inercia de un proceso, como lo supone Abbott (1997) respecto a las trayectorias tecnológicas, pues representa una serie de restricciones o rigideces conformada en el pasado sobre los conjuntos de oportunidades y elecciones presentes de los agentes individuales o colectivos que tienen capacidad para alterar o establecer una dirección o trayectoria tecnológica determinada, pero que no plantean forzosamente situaciones ordenadas e inevitables. La dependencia de la trayectoria representa encuadramientos específicos y particulares de las alternativas del desarrollo tecnológico; sin embargo, no determina las opciones de intercambio de los agentes correspondientes (Boas, 2007; David, 1985).

Con la evidencia presentada no se pretende describir o modelar los eventos específicos predecibles y contingentes que configuran la dependencia de la trayectoria del desarrollo tecnológico mexicano. Lo que se sugiere es que existe un patrón o dirección persistente en la actividad de patentamiento tanto de los agentes innovadores residentes como de los no residentes que permite aseverar que el cambio tecnológico en México durante ambos regímenes económicos se ha reforzado con decisiones y eventos de procesos tecnológicos pasados. ${ }^{3}$ Puesto que no se notan verdaderos cambios de sentido de las trayectorias en los resultados, esto da pie a suponer que los eventos reforzadores (llamados también mecanismos reproductores) han sido más intensos en relación con el dinamismo de los eventos contingentes en los procesos, tal como sugieren Vergne y Durand (2010).

Se tiene presente que los datos de patentes muestran ventajas y desventajas como indicadores tecnológicos. Estos datos exponen limitaciones para utilizarse como indicadores fieles de desarrollo de actividades tecnológicas de invención o innovación y de cambio tecnológico. No todas las invenciones se patentan ni son patentables y no todas las patentes solicitadas se otorgan debido al funcionamiento, reglas y modo de ejecución, de los regímenes de patentes. Tampoco todas las patentes llegan a explotarse y a traducirse en innovaciones, ni todas las patentes reflejan un grado de relevancia tecnológica o económica relativamente uniforme. Asimismo, no todos los sectores tecnológicos tienen la misma propensión a patentar (Mazzoleni y Nelson, 1998; OCDE, 2009). Sin embargo, se considera que las patentes aportan información útil para caracterizar aspectos rela-

\footnotetext{
${ }^{3}$ Para efectos de exposición se consideran residentes todos aquellos mexicanos que registraron patentes dentro del territorio nacional. No residentes se consideran todos los extranjeros que patentaron. La falta de más información impide hacer una categorización más refinada.
} 
cionados con las actividades tecnológicas debido a elementos diversos de información que recogen y a su disponibilidad, que comprende periodos temporales extensos. Además, es frecuente considerar las patentes como indicadores convenientes y aproximados de esfuerzos en inversión en protección de tecnologías desarrolladas, lo que lleva a que su estudio sugiera pautas muy vinculadas a los procesos económicos históricos de casi todos los países con un desarrollo industrial relativo, y así en cierto modo también revela los intereses y motivaciones circunstanciados de los agentes económicos o innovadores.

Para la construcción y presentación de las estadísticas de patentes se procedió de la manera siguiente. Para el periodo del patentamiento durante la ISI (1940-1970) se tiene elaborada una base de datos que toma como fuente de información primaria la contenida en las patentes concedidas publicadas en la Gaceta de la Propiedad Industrial. ${ }^{4}$ Para el periodo de intercambio liberalizado (1995-2015) los datos se toman y presentan de la información proporcionada por el Instituto Mexicano de la Propiedad Industrial (IMPI) en su Informe en cifras de 2016, aunque se trata de un informe que se publica anualmente desde $1994 .^{5}$ En el caso de las estadísticas de series anuales de patentes concedidas y los campos presentados como clase de residente o no residente y el tipo de persona legal de los dueños de las patentes, ambas fuentes de información son consistentes sistemáticamente y no presentan problema alguno para su ordenación, agrupamiento o análisis. En el agrupamiento por campos o sectores tecnológicos la información de los cuadros se presenta en el más alto nivel de agregación proporcionado por la CIP misma con que sistematiza la información el IMPI. ${ }^{6}$ Las patentes concedidas durante el periodo de la ISI no están clasificadas con el sistema mencionado, por lo cual se requirió una reclasificación de su nomenclatura tecnológica. La clasificación técnica de las patentes hecha por la oficina de patentes mexicana durante el periodo proteccionista seguía una nomenclatura numérica que correspondía a un método de clasificación conocido como clasificación australiana. Para poder llevar a cabo un ejercicio de comparabilidad se realizó la conversión de la clasificación australiana a la CIP mediante una tabla de equivalencia (Campa, 2016, cuadro 2, anexo metodológico, pp. 287-288). Con la reclasificación se establece una relación entre las dos clasificaciones en el nivel de clases y subclases de la CIP. Con ello se está en condiciones de agrupar los campos tecnológicos de las patentes de ambos periodos de manera actualizada y

\footnotetext{
${ }^{4}$ La base de datos comprende el número de cada patente, las fechas legales de solicitud, concesión y de prioridad, el nombre del titular o titulares y la clasificación tecnológica de las patentes.

${ }^{5}$ Disponible tanto en formato impreso como electrónico en la página web www.gob.mx/impi

${ }^{6}$ CIP consultada en OEPM (2006).
} 
uniforme, además de que es tal como se presenta en la fuente del IMPI. Con los resultados del agrupamiento se hace el estudio comparativo de la caracterización del desarrollo tecnológico mexicano prevaleciente durante ambos regímenes económicos.

En el apartado siguiente se realiza un repaso breve de los orígenes del patentamiento y el cambio institucional del régimen de patentes en México. En el apartado tres se presenta la evolución del agregado de patentes concedidas en el territorio nacional. En el cuarto se identifica la fuente territorial de las tecnologías patentadas. En el apartado quinto se examina el tipo de persona legal física o moral propietaria de las patentes. En el sexto se muestran los campos tecnológicos donde se agrupa el patentamiento, con lo que se caracteriza el tipo de cambio tecnológico nacional. En el último apartado se presentan las conclusiones.

\section{ORIGEN Y CAMBIO INSTITUCIONAL EN LA ACTIVIDAD DE PATENTAMiENTO EN MÉXICO}

El registro, uso y protección relativa de las patentes se iniciaron en el país con el establecimiento del Decreto-Ley de 1820, que fue el primer ordenamiento en materia de formación y protección de los derechos de propiedad de los inventores de tecnologías y con el cual se buscaba desplazar las prácticas y privilegios que representaba el ancien régime para el estímulo de las actividades inventivas o de innovación. ${ }^{7}$ A pesar de la nueva legislación y los cambios que registró en años sucesivos y que refinaron el paso de privilegios a derechos de propiedad, la actividad de patentamiento no mostró un dinamismo importante, sino hasta fines del siglo XIX. Entre 1853 y 1880 se otorgaron sólo 274 patentes en total acumulado. Las convulsiones políticas y sociales de la postindependencia, las invasiones extranjeras, los conflictos bélicos intestinos, además de un crecimiento económico lento, mercados estrechos y una alta marginación social de gran parte de la población, fueron factores que obstaculizaron un desarrollo intensivo del patentamiento en el país (Beatty, 1996, p. 584).

El punto de inflexión en la actividad de patentamiento nacional se manifiesta a partir de la década de 1880. Las tendencias internacionales en la modernización de los regímenes de patentes que priorizaban el fortalecimiento de los derechos de patente de los inventores reorientaron la política de patentes mexicana en ese sentido. Una política de patentes nueva y un crecimiento económico alto favorecido con la creación y ampliación de

${ }^{7}$ Para los interesados en el estudio histórico de los privilegios y su paso a patentes como derechos de propiedad, véanse por ejemplo Biagioli (2006) o Sáiz (1996). 
mercados, sobre todo del exterior, propició un crecimiento de la actividad de patentamiento de 13\% promedio anual entre 1880 y 1911, que pasó de un poco más de 100 patentes en 1888 a 1538 patentes en 1910. En esta fase de expansión e intensidad el perfil del patentamiento también mostró cambios importantes. La participación en el patentamiento de residentes era de 57\% en 1882, mientras que los no residentes poseían $41 \%$ del total de patentes registradas en el territorio nacional. Para 1910 el tamaño en el patentamiento de los residentes fue sólo de 25\% y el de los no residentes se amplió a 75\% (Beatty, 2002, pp. 134-136).

Las características de la actividad inventiva patentada durante esta etapa presentan dificultades para su comparación respecto de otros periodos de la historia económica mexicana. Sin embargo, podemos observar según los resultados presentados por Beatty (2002, pp. 138-139) que en el lapso de 1904 a 1907 el patentamiento entre residentes y no residentes se diferenció en relación con las actividades económicas prevalecientes. El patentamiento de residentes se concentró en actividades relacionadas con la química, donde alcanzó 14\%, en industrias del papel y publicidad con $11 \%$ y en actividades agrícolas con 9\%. Los no residentes se enfocaron en patentar en actividades como la minería y la metalurgia, donde la participación de las patentes fue de 15\%. Las patentes asignadas al sector de maquinaria abarcaron $12 \%$ y a procesos químicos, $10 \%$. Mientras que las patentes de residentes fueron atraídas a sectores económicos basados en el desarrollo de mercados locales, el patentamiento de no residentes se canalizó a actividades de exportación y a industrias pesadas, lo que muestra una divergencia relativa de intereses entre ambos grupos.

A inicios del periodo proteccionista, en enero de 1943, el régimen de patentes se reformó manteniendo y actualizando la orientación de protección fuerte de los derechos de patentes establecida en 1890-1903 durante el porfiriato y continuada con la reforma de enero de $1929 .^{8} \mathrm{La}$ legislación nueva introdujo la figura de patentes de mejora que protegía perfeccionamientos o mejoras de inventos ya patentados en propiedad de inventores primeros y verdaderos, aunque dichas patentes otorgaban los mismos derechos y obligaciones y el plazo de protección que las patentes de invención. Se perfeccionó el método de examinación de los inventos establecido con la reforma de 1929. Los costos monetarios del acceso al patentamiento y sus consecutivas modificaciones fueron relativamente bajos, aunque significaron una carga financiera menor para los no residentes que los residentes. Se dispusieron medidas de enforcement amplias y detalla-

\footnotetext{
${ }^{8}$ Para un análisis detallado de la legislación de patentes de 1890 y 1903, véanse Beatty (1996, 2001, 2002) y Beatty y Sáiz (2007); sobre la legislación de patentes de 1929 y 1943, véase Campa (2016).
} 
das, y el plazo de vigencia se redujo a quince años contados a partir de la fecha legal de solicitud contrario a los 20 años estipulados en la legislación anterior (Campa, 2016, pp. 88-107).

En junio de 1991 se estableció una legislación de patentes mexicana nueva, después de las reformas de 1976 y 1987, que incorporaba tempranamente los preceptos del TLCAN y las disposiciones del Acuerdo sobre los Aspectos de los Derechos de Propiedad Intelectual relacionados con el Comercio orientadas a la armonización de las legislaciones de patentes nacionales. En octubre de 1994 se llevó a cabo otra reforma sin alterar la dirección del ordenamiento precedente, que está vigente en la actualidad. Esta legislación ha reforzado todavía más el grado de protección de los derechos de patentes. Entre las disposiciones, que no contemplaba o eran de sentido opuesto en la legislación de patentes de 1943, se amplió el campo de materias patentables al incluir entre otros los productos químicos y farmacéuticos. Contempló por vez primera la figura de las patentes pipeline de particular interés del sector farmacéutico. El plazo de duración de las patentes se ha extendido a 20 años a partir de la fecha de solicitud, con opción de ampliación en tres años más en patentes farmacéuticas. Se aceptan los dictámenes de examinación de otras oficinas de patentes con arreglo a lo convenido en el Tratado de Cooperación en Materia de Patentes. Se ha eliminado la expropiación de las patentes. El derecho de registro de patentes se otorga ahora al primer solicitante (first-to-file) en lugar de al inventor primero y verdadero (first-to-invent). Se han suprimido las patentes de mejoras. Otra novedad es que se tiene estipulada la obligación de publicar las solicitudes de patentes en trámite después de un plazo de 18 meses contados desde la presentación (arts. 42, 52 y 54, Ley de Fomento, 27 de junio de 1991, pp. 4-30). Por otra parte, la ley de patentes actual no ha incorporado las importaciones paralelas como instrumento que favorece los derechos de usuarios. Tampoco comprende provisiones como la excepción Bolar y los costos de acceso han sido relativamente altos para los residentes (Shadlen, 2010, 2012). ${ }^{9}$

Los cambios que se pueden considerar como sustanciales con las reformas de la legislación de patentes en 1991-1994 respecto de la ley de patentes de 1943 corresponden a la patentabilidad de nuevos campos tecnológicos y al aumento del plazo efectivo en la protección de las patentes. Shadlen $(2010,2012)$ comenta que la incorporación de materias como los productos químicos y químico-farmacéuticos, no comprendidos en la le-

\footnotetext{
${ }^{9}$ Sobre los costos monetarios de acceso para el periodo de intercambio liberalizado en México, no hay estudios de caso o empíricos que analicen el impacto sobre la propensión a patentar. La alusión hecha aquí se basa en notas periodísticas de diarios de circulación nacional que eventualmente mencionan esta situación para los inventores mexicanos o residentes en el país.
} 
gislación de 1943 y de 1976, no sólo amplió campos nuevos a la propiedad exclusiva, sino también provocó -con la introducción de las patentes pipeline, que permitían la retroactividad de la vida legal de las patentes, y con la falta de provisiones de excepción tipo Bolar y de importaciones paralelas- una amplia prolongación del plazo de duración efectivo de las patentes y, por ende, según el autor, un fortalecimiento excepcional de los derechos de sus titulares.

Cabe señalar que el grado de protección o efecto de la ampliación de campos patentables como el de productos químicos y químico-farmacéuticos puede matizarse o relativizarse. Si bien la ley de patentes de 1943 prohibía el registro de patentes por estos productos, en la práctica había mecanismos que facilitaban su patentamiento. Por un lado, la legislación durante la etapa proteccionista permitía el patentamiento de composiciones de materia que incluyeran compuestos químicos, los cuales se tomaban como si fueran productos químicos. Por otro, aunque no contemplaba la concesión de patentes a los productos, sí permitía patentar procesos químicos. Esto posibilitaba que las patentes de origen extranjero que protegían productos químicos, como las que se solicitaban u otorgaban en Estados Unidos, pudieran ser solicitadas y concedidas en México como patentes de procedimientos químicos o farmacéuticos. En el momento de ejercer el derecho de prioridad en la oficina de patentes mexicana los agentes extranjeros recurrían a artificios legales para presentar las solicitudes como si fueran de procedimientos químicos, lo cual era una práctica generalizada y comúnmente aceptada (Campa, 2016, p. 206). El establecimiento de las patentes pipeline, el aumento del plazo nominal entre cinco y ocho años adicionales y la falta de disposiciones como la Bolar son novedades institucionales que han podido prolongar la protección efectiva de las patentes y tener un efecto importante en la propensión a patentar al aumentar las expectativas de apropiación segura de rentas, en particular para las empresas farmacéuticas transnacionales, como propone Shandlen, durante el régimen económico de intercambio liberalizado.

\section{EVOLUCIÓN DE LA ACTIVIDAD DEL PATENTAMIENTO DURANTE LA ISI Y EL INTERCAMBIO LIBERALIZADO}

El régimen de industrialización por sustitución de importaciones fue un modelo que, primero por la vía de los hechos y posteriormente mediante políticas más o menos explicitas, incentivaba una expansión y diversificación acelerada de los sectores productivos, en especial el del sector manufacturero. En esta etapa la economía nacional creció a una tasa promedio acumulada de $6.2 \%$, mientras que el sector manufacturero lo hacía a un 
ritmo de 10\%. La industria manufacturera pasaba de $15.4 \%$ en 1940 en la participación del PIB total a 23.7\% en 1970. La expansión industrial requirió la acumulación de cantidades importantes de capitales, lo que se reflejó en un aumento de la participación de la inversión en formación de capital fijo de 9 a 20\% en los años antes mencionados. Este periodo atestiguó un crecimiento elevado y sostenido, el cual se ancló en la incorporación de diversos tipos de tecnologías, tangibles e intangibles, dentro de fábricas y ramas industriales nuevas, o en la modernización de estructuras existentes. En este contexto, ¿cuál fue el grado y ritmo de innovación tecnológica registrado ante un acelerado y expansivo proceso de industrialización? La evidencia de las estadísticas de patentes nos ofrece un indicador, si bien parcial, de tal dinámica.

Para la segunda mitad del siglo Xx, la evolución del patentamiento en el país proveniente del registro de patentes concedidas indica que el nivel de actividad entre 1940 y 1970 fue relativamente bajo y no cobró dinamismo sino hasta la fase tardía del régimen proteccionista (véase gráfica 1).

En 1940, al comienzo del proceso de industrialización, el nivel de patentamiento en el país era de 863 patentes en total. En 1960 aumentó discretamente a 1066 patentes y no fue sino hasta el término del periodo en 1970 que la cifra de patentes llegó a 6 527. ${ }^{10}$ Tal evolución significó un crecimiento promedio anual acumulado de $7 \% .{ }^{11} \mathrm{El}$ cambio relativo elevado del patentamiento nacional, que coincide con el crecimiento elevado de la economía nacional y del sector manufacturero, sugiere la presencia de cierta asociación positiva entre ambas variables. ${ }^{12}$ Sin embargo, como notamos, el nivel bajo de registro de patentes caracterizó gran parte del periodo de la ISI, lo cual revela esfuerzos muy limitados de los actores interesados para completar hasta el final el ciclo del registro, plausiblemente debido a las fallas del régimen de patentes que gobernaba la actividad de patentamiento.

${ }^{10}$ En 1951 y 1967 se registran dos picos en la trayectoria de patentamiento, los cuales no tienen correspondencia con el estado de la economía o con cambios institucionales. Por consiguiente, dado el rasgo de outliers, suponemos que esto se debió a un cierto esfuerzo por parte de la oficina de patentes para actualizar los registros en la publicación de las patentes concedidas o a un intenso esfuerzo de abatimiento del rezago de patentes pendientes de conceder.

${ }^{11}$ El crecimiento fue calculado mediante la fórmula de la tasa de crecimiento anual compuesto, así como también por medio de regresión del logaritmo natural de la serie de patentes concedidas mediante el método de mínimos cuadrados ordinarios (MCO) con un $R^{2}$ de 0.526 . Sin variaciones significativas entre ambas tasas.

${ }^{12}$ No pretendemos establecer empíricamente una causalidad ni dirección en el sentido de si el patentamiento impacta el crecimiento económico o si son las variables económicas las que determinan el comportamiento del registro de patentes. Un debate sobre estos temas se encuentra, por ejemplo, en Griliches (1992). Sin embargo, los trabajos en investigación histórica han propendido más al segundo enfoque; véase, por ejemplo, la bibliografía citada en Sáiz (2002). En cierto sentido esta es la perspectiva que se aborda en el artículo. 


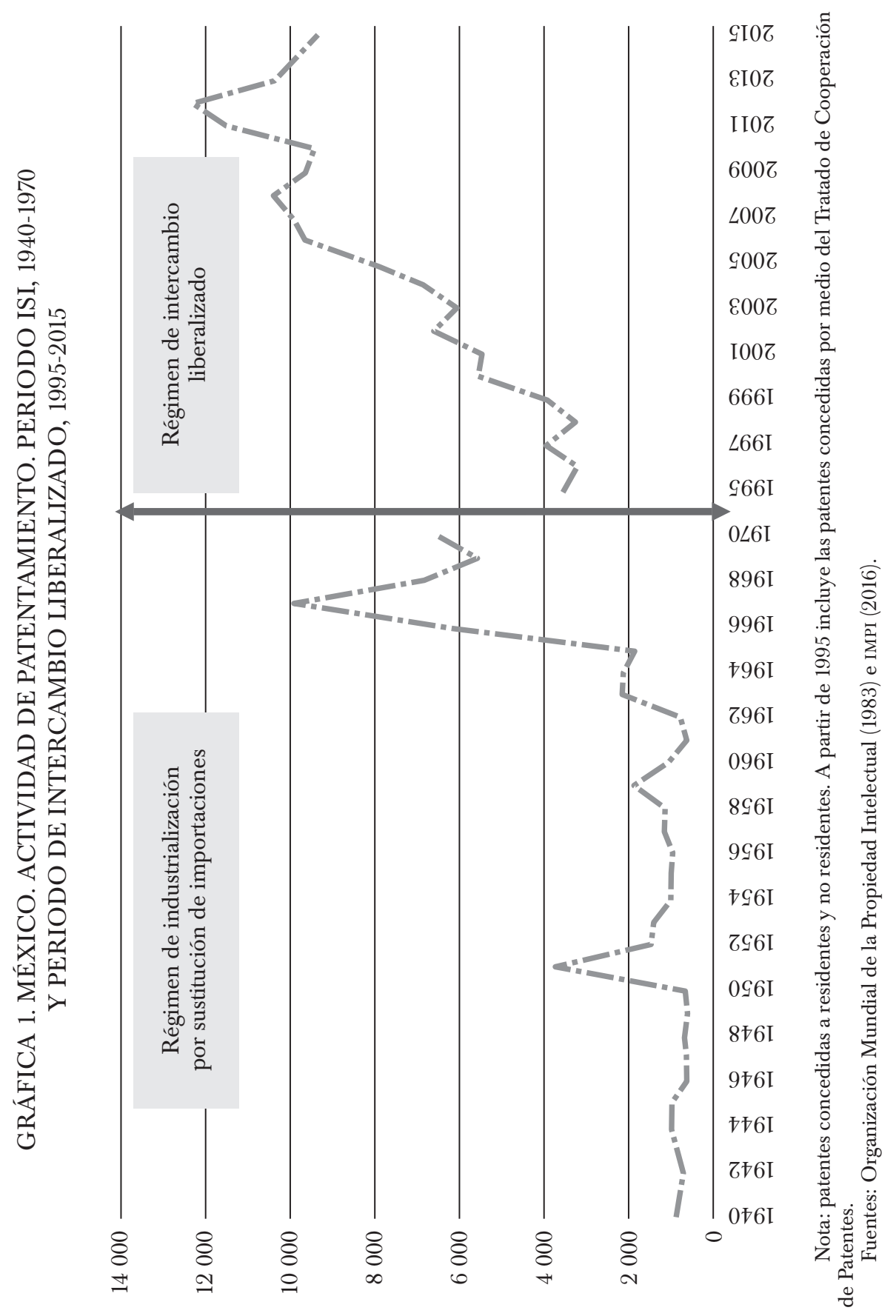


El régimen de patentes, como expusimos en el segundo apartado, en su aspecto formal o de jure brindaba una protección fuerte de los derechos de patentes a los titulares. Sin embargo, por la vía de los hechos o de fac$t o$, el proceso para obtener patentes era farragoso, con plazos dilatados y muy dispersos en el proceso de trámite entre la solicitud y concesión de las patentes. ${ }^{13} \mathrm{El}$ examen de las invenciones tenía un componente discrecional y poca transparencia en el proceso debido en parte a las cargas de trabajo elevadas y a los pocos examinadores de que disponía la oficina de patentes mexicana. Los mecanismos y procedimientos de enforcement de las patentes eran también bastante dilatados y contradictorios, pues las resoluciones tanto de la oficina de patentes como de los tribunales eran contrarias en general a los intereses y derechos de los titulares de las patentes y, cuando fallaban en su favor, las medidas de sanción e indemnización eran igualmente tardadas en su aplicación o ineficaces. Por ejemplo, en una docena de casos registrados tanto la oficina de patentes como los tribunales jurisdiccionales fallaron en contra de los titulares y anularon las patentes (Campa, 2016, cap. 5). ${ }^{14}$ Estas fallas en el diseño y funcionamiento se aplicaban a todo tipo de titulares, residentes como no residentes, si bien relativamente. Con todo, el funcionamiento del régimen de patentes rebajaba expectativas de beneficios y elevaba costos de transacción, lo que aminoraba los intereses de completar el ciclo de patentamiento para proteger, explotar, o beneficiarse de una adecuada apropiación de las rentas generadas por las creaciones tecnológicas y su aplicación en una economía en pleno crecimiento.

Con la liberalización de la balanza de pagos y la membresía y entrada en vigor del TLCAN en enero de 1994, se adoptó un régimen económico nuevo que gobierna el desenvolvimiento de la economía mexicana desde entonces. El proceso de reforma estructural ha alterado todos los sectores de actividad y en particular la orientación de la política y del aparato productivo del sector industrial. Se desmantelaron las empresas públicas y los instrumentos y programas de fomento y protección gubernamental establecidos durante el régimen de la ISI. Por el contrario, las estrategias nuevas de industrialización y modernización se han basado principalmente en la aplicación de políticas horizontales de corrección de fallas de mercado y de apoyo a ramas específicas orientadas a la dinámica comercial del

\footnotetext{
${ }^{13}$ Plazos que rondaban desde los 6.8 meses hasta 4.7 años en promedio en un año. Lo más significativo era la dispersión de los plazos, pues hubo casos en que, entre la solicitud y la concesión de una patente, el plazo fue de sólo dos días, mientras que, por ejemplo, en 1960, una patente fue otorgada pasados 30 años desde su solicitud en 1930 .

${ }^{14}$ Pasaban hasta cinco años antes de que los afectados pudieran solicitar a las autoridades jurisdiccionales las medidas de represión e indemnización correspondientes. Un estudio histórico de estos temas se encuentra en Arapostathis y Gooday (2013).
} 
exterior. De esta manera, el proceso de reconversión industrial llevado a cabo se ve reflejado con una contracción de la participación del PIB en manufacturas que en 1995 abarcaba 19.2\% del producto total, que disminuyó a 17.3\% en 2015. En este periodo el crecimiento de la industria de manufacturas fue de $2.8 \%$ y el de la economía en conjunto de sólo 2.9\%, reflejo también de los cambios dramáticos que ha representado el establecimiento de un régimen económico nuevo (Calderón y Sánchez, 2012).

En este contexto, al comienzo del periodo de intercambio liberalizado el grado de patentamiento era menor que el registrado en la fase última de la ISI. En 1995 se otorgaron 3538 patentes totales en el país, cuando en 1970 se habían concedido 6 527. La actividad de patentamiento registra una tendencia ascendente más temprano a lo largo de esta etapa comparada con la trayectoria de la ISI, pero no fue sino hasta el año de 2005 cuando se registraron 8098 patentes y se superó por primera vez el umbral alcanzado al final del régimen proteccionista. A lo largo del periodo de intercambio liberalizado el patentamiento registró una tasa de crecimiento promedio anual de 5\%. Este resultado es bastante más alto que el alcanzado en la producción nacional y manufacturera con $2.9 \%$ y $2.8 \%$ respectivamente. Entonces, a diferencia de lo ocurrido durante la ISI, parece que las condiciones económicas no son un factor que explique el ritmo del patentamiento en el periodo, aunque si comparamos los resultados de ambas etapas, notamos que se mantiene una asociación directa relativa entre variables con un crecimiento alto de patentes y PIB durante la ISI y un menor dinamismo en la relación patentamiento-producción en el periodo del intercambio liberalizado.

Las reformas de 1991-1994 al régimen de patentes, aunadas al establecimiento del Tratado de Cooperación en Materia de Patentes en 1995, fortalecieron el grado de protección de los derechos de propiedad de las patentes dentro del territorio nacional. Como señalamos anteriormente, la legislación nueva comprendió algunos cambios sustanciales que pudieron tener algún efecto en el grado o ritmo del patentamiento registrado durante el régimen económico liberalizado. Sin embargo, esto es complejo de determinar, puesto que en principio notamos que el nivel de patentamiento alcanzado en 1970 sólo fue superado a partir de 2005, a mediados del periodo del intercambio liberalizado, lo que sugiere que el régimen de patentes nuevo establecido a comienzos de la década de los noventa no tuvo un efecto inmediato en la propensión de los interesados a patentar. ${ }^{15}$

${ }^{15}$ Suponiendo, en función de la teoría, que las alteraciones de las tendencias de la trayectoria del patentamiento se producen con posterioridad a los cambios más significativos en las normas legales. Cabe recordar que la introducción de la ley de patentes de 1943 tampoco tuvo una influencia inmediata sobre la actividad de patentamiento y en este aspecto se observa una experiencia similar durante ambos regímenes económicos. 
Esto posiblemente se explique en parte otra vez por las condiciones del funcionamiento del régimen de patentes, en particular de la oficina de patentes, la cual se sigue caracterizando por mantener un rezago en el proceso de examinación y por consiguiente en la dilación de las concesiones de patentes. Además, se continúan observando limitaciones, ambigüedades y deficiencias en los mecanismos de protección, en particular los plazos muy prologados que transcurren para obtener los fallos de las autoridades jurisdiccionales y las medidas punibles y de indemnización (Castro, Pacón y Desiderio, 2012).

Por otra parte, la tasa de crecimiento de la economía y la del sector industrial han sido relativamente bajas, lo cual entonces no se consideraría un aliciente muy atractivo como para que los agentes mantuvieran el interés por completar el ciclo de patentamiento. Sin embargo, el nivel de patentamiento ha aumentado de manera sostenida relativamente desde mediados de la primera década de 2000 (véase gráfica 1). Este puzzle quizá encuentre cierta aclaración, como señala Shadlen (2010), al considerar que el régimen de patentes no comprendía provisiones como la "Bolar" y la de importaciones paralelas, lo cual dio paso para que el plazo efectivo de la protección de las patentes se ampliara excepcionalmente más allá de los estándares internacionales propuestos en el Acuerdo sobre los Aspectos de los Derechos de Propiedad Intelectual relacionados con el Comercio. En especial se puso a prueba el diseño institucional en 2003 con una iniciativa de reforma que buscaba la reducción del plazo de protección de las patentes a sólo diez años y hacer efectivo el instrumento de licenciamiento obligatorio ante situaciones de emergencias de salud. Este proyecto de reforma no sólo fue descartado, sino que se minó todavía más la efectividad, ya de por sí precaria, del licenciamiento obligatorio con la contrarreforma (Shadlen, 2010, pp. 829-832). ${ }^{16}$ Para 2004 se hacía evidente la inoperancia de este mecanismo y el reordenamiento y control restrictivo del mercado de medicamentos genéricos. Por consiguiente, puede no ser una simple coincidencia que en 2004 el patentamiento haya recuperado el registrado en 1970 y que a partir de 2005 se observe una tendencia creciente más pronunciada del nivel de actividad. ${ }^{17}$

En resumen, en el periodo de la ISI la expansión de la actividad de patentamiento ocurrió hasta la fase tardía de la época proteccionista. Por consiguiente, las reformas al régimen de patentes parece que no tuvieron

${ }^{16}$ La contrarreforma se incorporó en el medio institucional del sector salud mexicano no en la legislación de patentes.

${ }^{17} \mathrm{La}$ alusión tiene que tomarse con cautela porque presupone que el sector farmacéutico, principal beneficiario de los recovecos del régimen de patentes, es el actor principal responsable del impulso a la actividad de patentamiento, lo cual no es posible precisar con la evidencia disponible. Sin embargo, en apartados posteriores presentamos algunas exploraciones. 
un efecto inmediato y significativo sobre la propensión a patentar. Por lo tanto, es plausible considerar que fueron las condiciones económicas favorables imperantes a lo largo del periodo, tal como Beatty lo propone para la época del porfiriato, las que influyeron en el dinamismo de la actividad. Durante el régimen económico orientado a la apertura de mercados la actividad de patentamiento también mostró inicialmente un nivel bajo, que aumentó de manera significativa hasta mediados del periodo. El ritmo de crecimiento del patentamiento fue menor al observado durante la ISI, pero fue superior al registrado por la economía, por lo que, contrario a lo ocurrido durante el periodo proteccionista, las condiciones económicas del intercambio liberalizado no parecen haber sido un factor que haya estimulado la propensión de los interesados a patentar a lo largo del periodo. En cambio, ciertas características de la legislación establecida en la década de 1990 como las patentes pipeline y la falta de provisiones favorables a los procesos de innovación y de derechos de los usuarios al parecer repercutieron en las expectativas de beneficio de los agentes titulares de patentes, en particular de las empresas extranjeras, debido a un aumento potencial en el grado de protección de la apropiación de rentas probablemente de un origen distinto al productivo, tal como sugiere Shadlen.

\section{Fuente DE LA TITULARIDAD DE LAS PATENTES}

En este apartado presentamos el nivel de actividad de patentamiento registrado por dos grupos distintos, residentes o mexicanos y no residentes o extranjeros, con el fin de ir perfilando cómo respondieron a los estímulos de los cambios de regímenes económicos y de patentes. A comienzos del periodo de la industrialización proteccionista la propiedad de las patentes mostraba un relativo balance en las participaciones de residentes y no residentes. En 1940, 51\% de las patentes totales correspondieron a residentes y los no residentes obtuvieron $49 \%$ del total (véase cuadro 1). Sin embargo, a lo largo del periodo y al finalizar la etapa de la ISI el patentamiento de residentes declinó en importancia al caer hasta sólo 5\% del total de patentes concedidas en 1970, mientras que los no residentes obtuvieron $95 \%$ de todas las patentes otorgadas dentro del territorio nacional.

La tendencia se perpetuó durante el periodo de intercambio liberalizado. Las patentes en propiedad de residentes mantuvieron un nivel muy bajo de participación a lo largo del periodo, entre dos y 4\% del total. Del mismo modo, los no residentes han poseído más de $95 \%$ de todas las patentes. Esta caracterización sugiere que el funcionamiento del régimen de patentes ha sido un medio de interés permanente básicamente para agen- 
CUADRO 1. MÉXICO. PATENTES CONCEDIDAS A RESIDENTES

Y NO RESIDENTES EN LOS DOS RÉGIMENES ECONÓMICOS, AÑOS SELECCIONADOS

\begin{tabular}{|c|c|c|c|c|c|}
\hline$A \tilde{n} o$ & Total de patentes & Residentes & Porcentaje & No residentes & Porcentaje \\
\hline \multicolumn{6}{|c|}{ Régimen de industrialización por sustitución de importaciones } \\
\hline 1940 & 863 & 438 & 51 & 425 & 49 \\
\hline 1950 & 646 & 214 & 33 & 419 & 65 \\
\hline 1960 & 1066 & 96 & 9 & 970 & 91 \\
\hline 1970 & 6527 & 342 & 5 & 6185 & 95 \\
\hline \multicolumn{6}{|c|}{ Régimen de intercambio liberalizado } \\
\hline 1995 & 3538 & 148 & 4 & 3390 & 96 \\
\hline 2000 & 5519 & 118 & 2 & 5401 & 98 \\
\hline 2005 & 8098 & 131 & 2 & 7967 & 98 \\
\hline 2010 & 9399 & 229 & 2 & 9170 & 98 \\
\hline 2015 & 9338 & 410 & 4 & 8928 & 96 \\
\hline
\end{tabular}

Fuente: elaboración con datos propios para los años seleccionados de 1940 a 1970 con base en IMPI (1940-1970); para 1995-2015, IMPI (2016).

tes extranjeros, incluso ante diferencias en los cambios de incentivos que han establecido los dos regímenes económicos.

Según se observa, cada grupo respondió a las reformas legales y los cambios en las condiciones económicas de modo diferenciado. Se distinguen dos tendencias claras persistentes a lo largo de 75 años de actividad de patentamiento nacional. ${ }^{18}$ Un progresivo declive de la presencia de residentes en el registro de patentes y una enorme expansión de la cantidad de patentes en propiedad de no residentes. ${ }^{19}$ Si la economía nacional ha registrado en episodios históricos diversos un importante crecimiento ¿por qué tales condiciones no han estimulado con amplitud el interés por patentar de los residentes? ¿El régimen de patentes representa para este grupo más costos que beneficios? ¿Los no residentes han predominado en el patentamiento aprovechando únicamente los estímulos que ofreció la producción nacional con base en la sustitución de importaciones o por

${ }^{18}$ Referimos a este horizonte temporal porque las participaciones de ambos grupos prácticamente se mantuvieron igual durante el lapso intermedio que comprende las décadas de 1970 y 1980. Véase Aboites y Soria (2008).

${ }^{19}$ Esta experiencia ha sido similar en otros países, por ejemplo, en Argentina, donde en 1968, $75 \%$ de las patentes estaban en manos de extranjeros y 50\% se concentraba en empresas transnacionales (Katz, 1980). 
las oportunidades que se han presentado con la apertura, privatización y desreglamentación del periodo de intercambio liberalizado? Tratamos de explorar estos aspectos en los apartados siguientes.

\section{TIPO DE TITUlAR DE LAS PATENTES}

La titularidad de las patentes concedidas en México varió de manera significativa entre grupos de residentes y no residentes. Esto nos lleva a aproximarnos a identificar los intereses y la reacción de la propensión a patentar de los agentes ante los cambios en incentivos tanto de los regímenes económicos como de las políticas de patentes. A comienzos de la ISI el patentamiento registrado por residentes fue un asunto de inventores individuales (véase cuadro 2). El 94\% del total de las patentes otorgadas correspondieron a este grupo en 1940 y para el fin del periodo proteccionista mantenía 82\% en la participación. En contraste el sector empresarial registró una presencia muy baja en todo el periodo y alcanzó una tasa de 17\% al final de este en 1970. Los no residentes mostraron un comportamiento opuesto a los residentes. Las corporaciones extranjeras predominaron en el patentamiento durante todo el periodo. Si al inicio de la sustitución de importaciones la participación de este colectivo alcanzó 58\%, para el fin del periodo abarcaron $91 \%$ de la titularidad de las patentes. La participación de los individuos no residentes dueños de patentes declinó de $42 \%$ en 1940 a 8\% en 1970. En ambos grupos, residentes y no residentes, la participación de las organizaciones no corporativas (centros de investigación, agencias públicas, universidades, fundaciones, etc.) fue apenas perceptible y residual al final del periodo de la ISI.

Durante la vigencia del régimen económico liberalizado se notaron cambios importantes en la estructura de participación en el patentamiento. En el grupo de los residentes se puede observar una tendencia descendente más pronunciada del patentamiento de individuos a lo largo del periodo de 51 a 30\% entre 1996 y 2015. El empresario mexicano prácticamente ha estancado el interés por patentar registrando el mismo grado de participación entre el inicio y el fin de la etapa con 32\%. Mientras tanto, el sector no corporativo ha incrementado significativamente su presencia en el patentamiento al poseer 38\% del total de patentes de los residentes al final del periodo en 2015. Los no residentes manifestaron un comportamiento diferente que reveló una cierta estabilidad relativa en las proporciones del patentamiento. La participación de los individuos extranjeros sigue mostrando una reducción de cinco a 3\% en las patentes en 2015. Las corporaciones elevan ligeramente su participación de 95 a 96\%, mientras que 


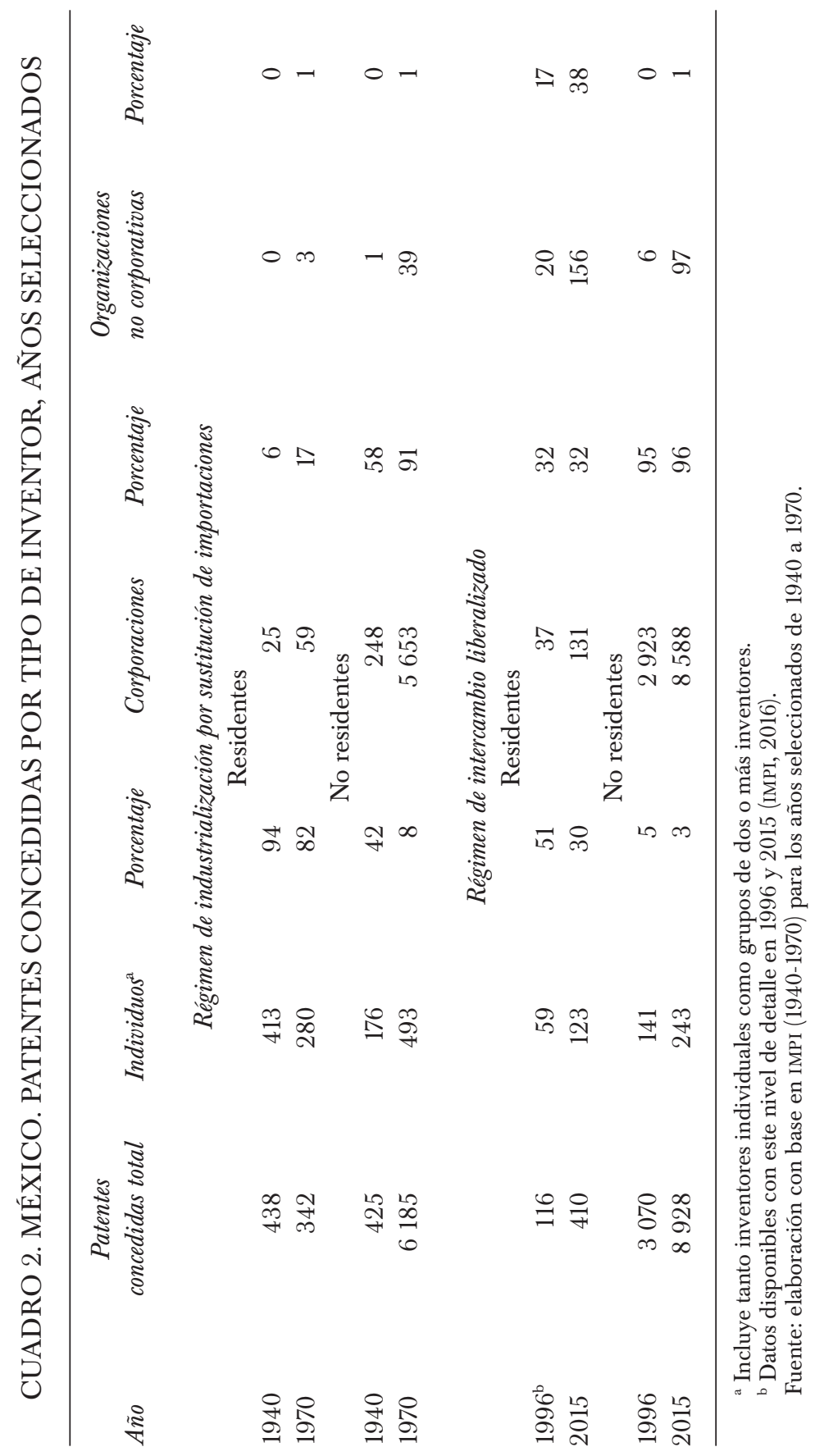


las organizaciones no corporativas siguen registrando un patentamiento residual a lo largo del periodo.

$\mathrm{Al}$ contrastar los resultados del periodo largo observamos los siguientes trazos en el interés o propensión a patentar de los actores identificados. En el grupo de los residentes se puede ver una tendencia descendente del patentamiento de individuos a lo largo de los dos periodos. Así, de haber registrado 94\% de participación en 1940, el patentamiento de este colectivo pasó a 30\% en 2015. Por su parte, si bien la participación de las empresas residentes en el país se incrementó de 6 a 17\% durante la ISI y llegó a alcanzar 32\% para el fin del periodo largo en 2015, hay un estancamiento en el grado del patentamiento desde 1996. En contraste, el colectivo de organizaciones no corporativas emerge de manera significativa durante el periodo de intercambio liberalizado. Aunque en el periodo de la ISI su participación fue residual, al comenzar la etapa de intercambio liberalizado ya registraba una presencia de $17 \%$ en 1996 , que pasó a 38\% en 2015 en el patentamiento de residentes y superó en este lapso último incluso al patentamiento de individuos y de empresas. En el caso de los no residentes la tendencia del patentamiento es más consistente. Tanto al final de la ISI como durante el periodo de intercambio liberalizado el tamaño de la participación de los individuos fue muy pequeño. En 1970 ya era de $8 \%$ y en 2015 se redujo más, a sólo 3\%. El sector empresarial mostró una tendencia similar pero creciente. De 91\% en 1970 su participación en el patentamiento se amplió todavía más a 95\% en 1996, y se mantuvo relativamente estable en 2015 con $96 \%$. Es de notar que, contrario al comportamiento de los residentes, el patentamiento de las organizaciones no corporativas de los no residentes se mantuvo marginal durante el periodo de intercambio liberalizado con $1 \%$ al final del periodo, en un nivel que ya había alcanzado en 1970 .

Vemos claramente que, en el caso de los no residentes, las corporaciones extranjeras han sido las que más han patentado a lo largo de los dos periodos. Pero, además, paulatinamente han predominado en el patentamiento total. En 1940 los 248 títulos que poseían representaban sólo 29\% de todas las patentes otorgadas en territorio nacional. Para 1970 este porcentaje aumentaba a un espectacular 87\%. En 1996 se registró una contracción pequeña con 83\%, pero al final del periodo en 2015 se concentró todavía más el patentamiento de este colectivo con $92 \%$ de todas las patentes nacionales. Además del crecimiento de la economía en conjunto, la apertura y expansión de los mercados atrajo una cantidad importante de inversión extranjera directa y de importaciones de bienes tangibles variables, que pueden contribuir a explicar el predominio de este colectivo en el patentamiento. Durante la ISI se observó un aumento muy significativo de flujos de capital extranjero y de importación de productos debido en 
parte a la política asumida a mediados-fines de la década de 1950 de sustitución avanzada de bienes de consumo duradero, intermedios y de capital y la conformación de industrias modernas y dinámicas, lo cual fue un estímulo importante a la atracción de patentes, ya sea que tuvieran relación con la explotación directa o mediante la protección de los mercados de explotación. Por ejemplo, el monto de inversión extranjera directa pasó de 566000000 de dólares en 1950 a 2822 millones de dólares en 1970, lo que representó un crecimiento de $8 \%$. Mientras tanto, las importaciones de bienes de capital llegaron a constituir 23\% de la formación bruta de capital fijo y alcanzaron un crecimiento de 11\% entre 1960 y 1970 (Aboites, 1989; Sepúlveda y Chumacero, 1973). Para el periodo del intercambio liberalizado, la dependencia de flujos del exterior se acentuó debido a la prioridad que le otorgó a este sector el régimen económico nuevo al considerarlo como ancla o motor para el crecimiento. Si bien tuvo un crecimiento menor comparado con el periodo de la ISI, pues registró una tasa de $6 \%$ entre 1995 y 2015, en términos del volumen de inversión ha sido mucho más alto al pasar de $0.6 \%$ de participación de la inversión extranjera directa en el PIB total en 1970 a $2.5 \%$ en 1996 y $1.8 \%$ en 2014 (Secretaría, 2016). ${ }^{20}$

Por otra parte, como mencionamos con anterioridad, el régimen de patentes, tanto el vigente durante la época de sustitución de importaciones como el que gobierna el periodo de intercambio liberalizado, aunque no ha estimulado efectivamente la actividad de patentamiento al menos no ha obstaculizado la propensión a patentar de las corporaciones transnacionales dadas sus capacidades económicas y de representación legal para sortear las fallas o costos de transacción en el proceso de concesión o protección. Además, los cambios en el grado de protección en el régimen de patentes, con todo y las permanentes deficiencias en su funcionamiento, en ambos periodos han seguido siendo considerados propicios en cierto modo para las expectativas del sector privado extranjero en su interés por inferir y capturar las ventajas del ambiente de negocios nacional.

El empresariado mexicano ha reflejado una participación notoriamente baja en el patentamiento nacional a lo largo de ambos periodos. ${ }^{21} \mathrm{Se}$ supone que este colectivo se ha situado en el mismo entorno económico favorable de proteccionismo y crecimiento elevado y sostenido durante la ISI o de acceso a mercados y oportunidades nuevas resultado de la apertura comercial del régimen de intercambio liberalizado. Pero no se observa

${ }^{20}$ Se nota, sin embargo, una reducción de la inversión extranjera directa al final del periodo. Esto y el menor ritmo de crecimiento se debe a las fluctuaciones importantes que ha registrado el flujo de capitales externos como resultado en parte de las crisis, local y exterior, que se han manifestado en ciertos años a lo largo del periodo.

${ }^{21}$ En especial si se considera que el empresario privado es el agente de cambio principal en las estructuras económicas. 
que haya respondido intensamente en grado a los incentivos establecidos. Entre los factores que explican, en cierto modo, el interés o propensión de este colectivo a patentar poco figuran: la composición de la estructura empresarial donde el tamaño de las empresas puede significar restricciones o debilidades de capacidades financieras o de inversión en esfuerzos de investigación o para enfrentar los costos de acceso al patentamiento; la tendencia a registrar capacidades escasas para vincularse con los centros de investigación públicos o privados; el desconocimiento o poco interés por proteger los adelantos tecnológicos que genera; el optar por proteger sus tecnologías mediante instrumentos diferentes a las patentes, como los secretos. Sin embargo, el elemento más consistente que explica el bajo nivel de actividad de patentamiento de los empresarios mexicanos ha sido su escaso interés histórico por producir una oferta amplia e intensiva de tecnologías nuevas patentables, y su preferencia por comprarlas en el exterior antes que invertir en esfuerzos de investigación propios (Campa, 2016; Castañeda, 2010; Haber, Razo y Maurer, 2004; Jeannot, 2001; Pérez, 1996; Rossi, 1977; Tornell, 2002).

El comportamiento del patentamiento de individuos residentes y no residentes es también complejo de explicar. La tendencia descendente de la participación en la actividad de registrar patentes en ambos grupos puede explicarse en cierto modo también con los factores que afectan a los empresarios y emprendedores pequeños, en particular con la presencia de cambios en las condiciones económicas con periodos de crecimiento, pero a su vez con lapsos de crisis recurrentes y agudos. Otra explicación es que estos colectivos son desplazados por las corporaciones transnacionales que poseen y controlan acervos tecnológicos ingentes y relevantes que les permiten negociar muy favorablemente u obstaculizar el surgimiento de adelantos tecnológicos independientes, en especial de las invenciones acumulativas. Finalmente, debido a que el régimen de patentes nacional no discrimina de manera eficaz para incentivar la propensión a patentar de emprendedores aislados o pequeños, en particular respecto al abaratamiento de los costos de acceso por solicitar y obtener patentes y de manera importante de los costos de asesoramiento y representación que la tramitología estipula. Esto ha sido un factor central del que han sido afectados los residentes especialmente durante el periodo de intercambio liberalizado. ${ }^{22}$

${ }^{22}$ No se han hecho estudios detallados que comprendan todos los costos monetarios contemplados en el proceso de patentamiento mexicano y sus efectos sobre la propensión a patentar. Una aproximación para el periodo de la ISI se encuentra en Campa (2016). Para el periodo del porfiriato, Beatty y Sáiz (2007) presentan un análisis empírico del costo del patentamiento, pero sólo comprende también las tarifas estipuladas para el registro de patentes por las autoridades mexicanas. 
La evolución de las organizaciones no corporativas o centros de investigación sin fines de lucro de los residentes y no residentes es un fenómeno también por dilucidar. Durante la ISI el patentamiento, aunque residual, se llevó a cabo casi en su totalidad por los no residentes que aprovecharon la expansión industrial más que los incentivos del régimen de patentes (Campa, 2015). Con la vigencia del modelo de intercambio liberalizado, los centros de investigación de residentes han emergido como un actor principal en la actividad de patentamiento. Una explicación plausible es el esfuerzo de agentes como las universidades locales, por ejemplo, la Universidad Nacional Autónoma de México, la Universidad Autónoma Metropolitana y el Instituto Politécnico Nacional, que desde la década de 1980 comenzaron a prestar atención y desarrollar políticas propias sobre patentamiento y de transferencia de tecnología. Estas políticas se correspondieron y encuadraron también dentro de los avances concretados en la formulación e implantación de la política tecnológica o sistema nacional de innovación (Casas y Luna, 1997; García y Heijx, 2012).

\section{Perfil tecnológico del Patentamiento ENTRE REGÍMENES ECONÓMICOS}

En este apartado hacemos un bosquejo del desarrollo tecnológico en México a través de la actividad de patentamiento durante los regímenes de industrialización protegida y de apertura económica. La transición de un régimen económico a otro implicó una alteración de los incentivos que modificó sustancialmente la dinámica de las estructuras productivas en general y del sector industrial en particular y con ello también los procesos de incorporación de tecnologías. El asunto es identificar cómo la actividad de patentamiento ha evolucionado dentro de cada régimen económico y cómo ha reaccionado ante los cambios de orientación de las condiciones económicas. Con ello buscamos encontrar patrones que muestren si hubo continuidades o rupturas en esta dinámica.

El cuadro 3 muestra la actividad de patentamiento agrupada por sectores tecnológicos realizada por los residentes en México durante el periodo de la ISI y el de intercambio liberalizado. Podemos observar que el perfil del desenvolvimiento tecnológico caracterizado por este colectivo ha mantenido una estructura y evolución no muy diferente a lo largo de los dos periodos. Durante la ISI los acervos de tecnología patentada se concentraron en los campos relacionados con necesidades corrientes de la vida; técnicas industriales diversas; transportes y de mecánica; ilumi- 


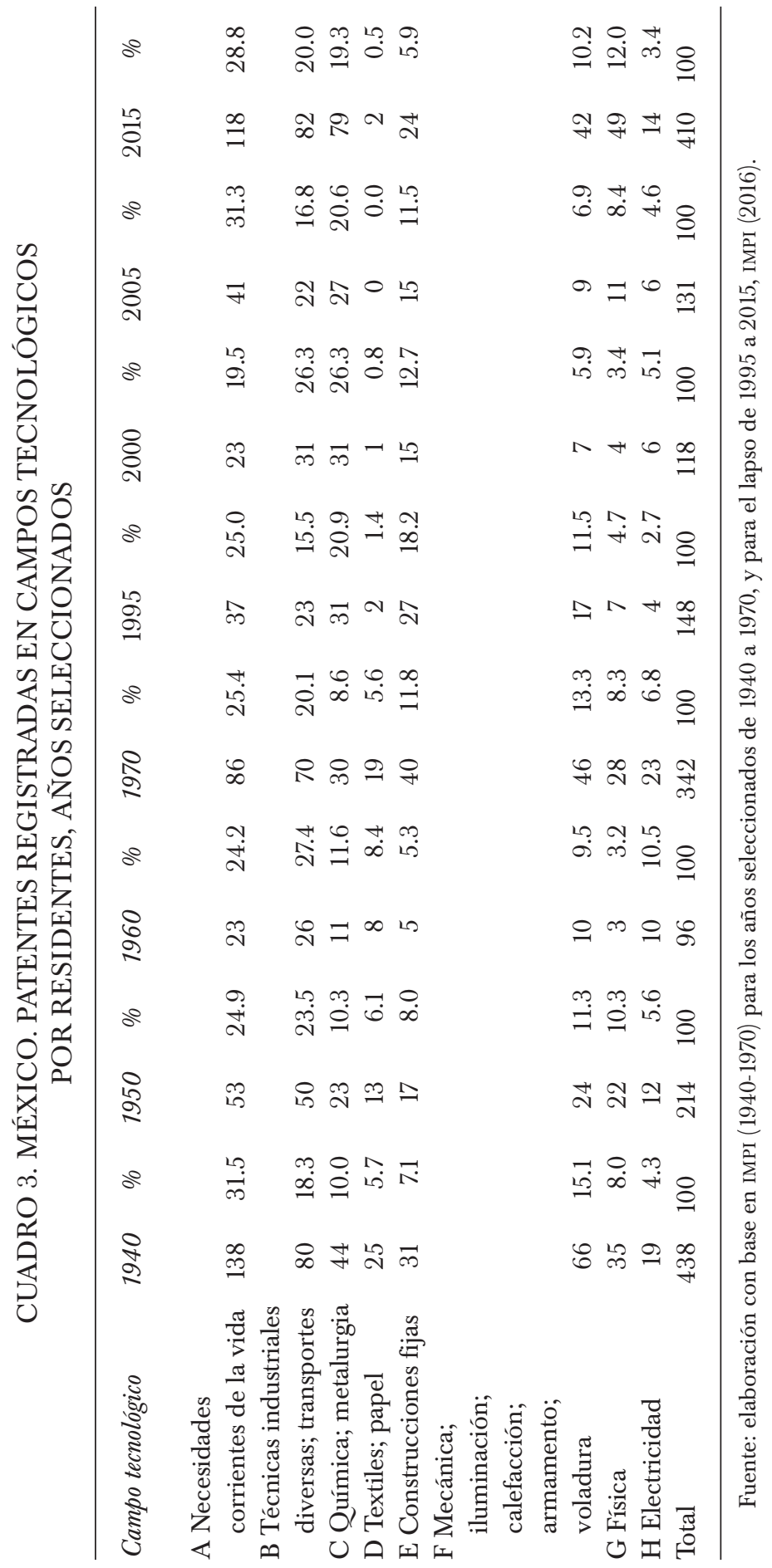


nación. ${ }^{23}$ Aunque las participaciones de estos campos presentaron fluctuaciones ligeras en su posición, mantuvieron la tendencia de concentración del patentamiento. En la etapa de intercambio liberalizado básicamente se mantuvo una estructura similar, salvo que el campo de química-metalurgia se posicionó en un grado más alto y desplazó al campo de mecánica y antepuso su participación a la registrada por el campo de técnicas industriales. ${ }^{24}$ Las tendencias relativamente estables del patentamiento por campos tecnológicos de este grupo durante cada etapa económica sugieren que el interés o propensión a patentar no fue trastocado de manera importante.

La comparación entre periodos sugiere también continuidades en los intereses de patentar. En 1940 al inicio de la ISI el patentamiento en el campo de necesidades corrientes de la vida alcanzó 32\% del total y en 2015, año final del periodo de intercambio liberalizado, el registro de patentes fue de $29 \%$ del total (véase cuadro 3). En el campo de técnicas industriales diversas; transportes tuvo una presencia de 18.3 y $20 \%$ en los años antes indicados, mientras que el campo de mecánica alcanzó $15.1 \%$ al inicio del periodo largo y mostró un descenso constante hasta llegar a 10.2\% en 2015. El campo de química-metalurgia mantuvo una participación debajo del campo de mecánica durante el proteccionismo, pero emergió en el periodo de intercambio liberalizado y concentró el patentamiento al duplicar su participación, que pasó de 10\% en 1940 a 19.3\% en 2015 .

De manera similar los campos tecnológicos que mostraron las participaciones más bajas en el periodo de 1940-1970 correspondieron también a los reflejados durante el periodo 1995-2015. Los campos de "textiles; papel" y "electricidad" alcanzaron las proporciones más bajas dentro de todo el conjunto durante todo el periodo largo de 1940 a 2015, excepto en el lapso de 1960. El campo de "textiles; papel" tuvo más presencia durante la ISI y alcanzó una proporción hasta de $8.4 \%$ en la década de los cincuenta. Pero para la etapa de intercambio liberalizado este campo muestra un tamaño muy pequeño, prácticamente residual entre 2005 y 2015, con tan sólo $0.5 \%$ del total de patentes registradas. El campo tecnológico de "electricidad" ha sido el otro con menor presencia dentro de la estructura tecnológica de patentamiento de residentes. ${ }^{25}$ Sus participaciones han $\mathrm{cu}^{-}$

\footnotetext{
${ }^{23}$ Según la CIP el campo de necesidades corrientes contempla áreas como actividades rurales, alimentación, tabaco, vestimenta, calzado, higiene, deportes, etc. El campo de técnicas industriales incluye áreas como separación, mezcla, conformación, imprenta, transportes y nanotecnología. El campo de mecánica comprende máquinas, motores, aparatos de combustión, refrigeración, hornos, estufas, armas, municiones, etc. (Oficina Española de Patentes y Marcas, 2006).

${ }^{24} \mathrm{El}$ campo de química-metalurgia incluye química inorgánica y orgánica, tratamiento de metales, etcétera.

${ }^{25}$ Campo que considera elementos, producción, circuitos electrónicos, etcétera.
} 
bierto de $4.3 \%$ en 1940 a $3.4 \%$ en 2015 del total, lo que refleja una relativa estabilidad en las proporciones durante el periodo largo.

Los resultados anteriores indican que, durante la vigencia de los dos regímenes económicos, prácticamente se mantuvo la dirección de la propensión de los residentes a patentar en los campos tecnológicos mencionados, y muestra así una continuidad en el grado de concentración del patentamiento. Se advierte también que no hubo cambios importantes en las estructuras, lo que da origen a campos tecnológicos diferentes, salvo el de la química, en el periodo largo. Esto sugiere que el desarrollo de las actividades tecnológicas realizadas por residentes no ha sido tan dinámico y se vislumbran conexiones limitadas o flujos compartidos restrictivos de información tecnológica entre sectores. Por otro lado, con los datos de patentes y la información disponible, no podemos establecer la relevancia tecnológica de los inventos patentados, ni identificar la evolución de la complejidad tecnológica y los avances cualitativos propios de los productos y procesos protegidos en las patentes, ni conocer el modo y el grado en que provinieron los esfuerzos para generar las tecnologías, es decir, si fueron producto y en qué medida de la aplicación de capacidades ingenieriles, destrezas y conocimientos prácticos o de esfuerzos bien estructurados y sistemáticos en inversiones en I+D. Sin embargo, es plausible suponer que, durante la ISI, el patentamiento de residentes ha estado más ligado a capacidades del primer tipo dado el predominio de los inventores individuales dueños de patentes (Mercado y Lombó, 1982). Mientras que, durante el periodo de intercambio liberalizado, el patentamiento es resultado de esfuerzos más centrados en el desarrollo sistemático de actividades de investigación dada la creciente complejidad del estado de la técnica, la colaboración especializada de equipos de trabajo con formación científica y tecnológica elevada, además de los vínculos cada vez más cercanos entre investigación e industria, tal como lo sugiere la emergencia de las organizaciones no corporativas en la actividad de patentamiento (Katz, 1980).

En el cuadro 4 se presenta el patentamiento por campos tecnológicos de los no residentes. En este grupo las patentes se concentraron relativamente en los campos de técnicas industriales diversas, transportes de necesidades corrientes de la vida y de química-metalurgia. Del mismo modo que con el grupo de residentes, las participaciones del patentamiento de los no residentes en estos campos mostraron fluctuaciones ligeras en su posición, pero conservaron la tendencia de concentración de la actividad. Tanto en el régimen de la ISI como en la etapa de intercambio liberalizado, los tres campos tecnológicos anteriores abarcaron más patentes. En el primer régimen económico en 1940 la participación acumulada en el registro de patentes totales fue de 54.9\% y para 1970 fue de 67\%. En el segundo régimen económico, la concentración de patentes de estos tres sectores 


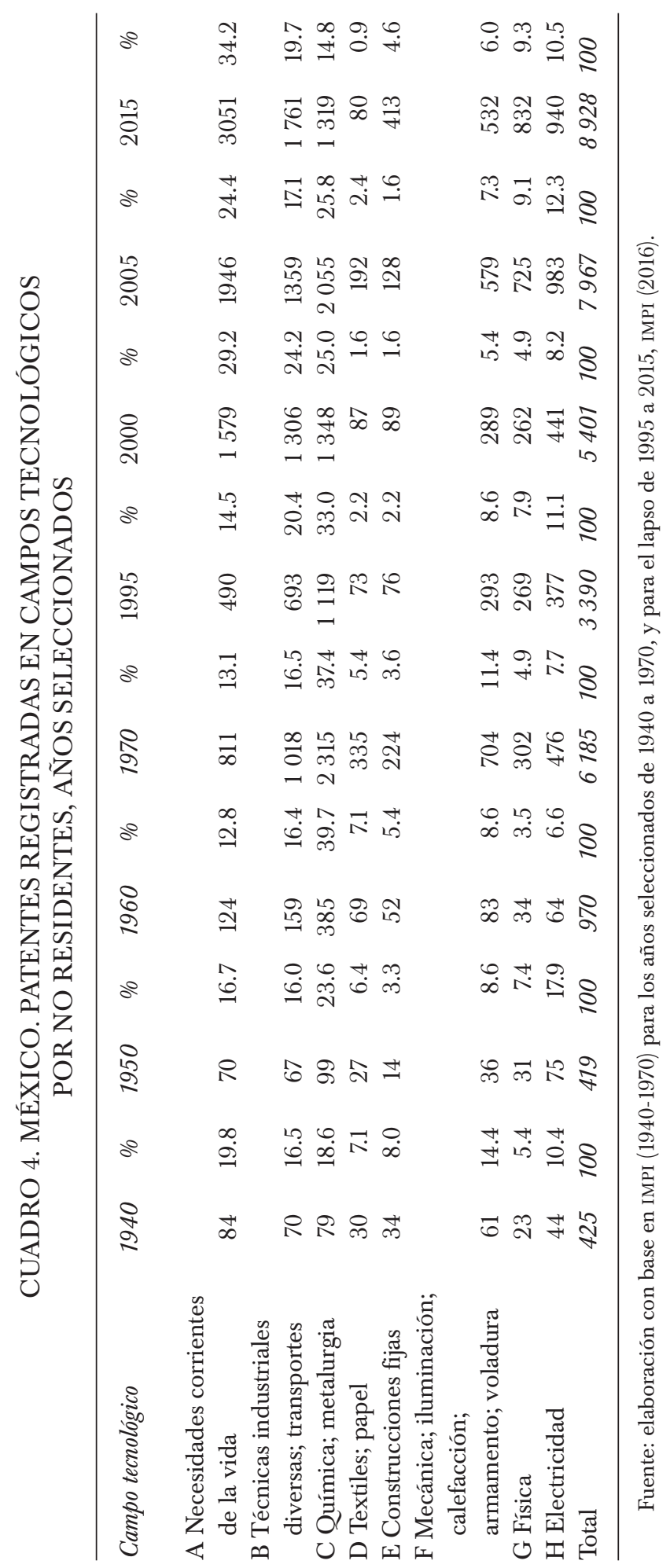


fue de $68.7 \%$ en 1995 y de $76.7 \%$ en 2015, lo que reflejó una tendencia creciente en la concentración.

En el régimen de la ISI el campo tecnológico de química-metalurgia fue el que aglutinó más patentes de los no residentes. En 1940 abarcaba 18.6\% y al finalizar en 1970 registró un aumento de 37.4\%. El campo de técnicas industriales fue el más estable al comprender 16\% de las patentes en prácticamente todo el periodo. En el campo de necesidades corrientes de la vida el registro al inicio del proteccionismo fue de 19.8\% y mostró una reducción de $13.1 \%$ al final, pero sin perder su posición ante otros grupos diferentes. Para el periodo del intercambio liberalizado el patentamiento de los no residentes se concentró más en el campo de necesidades corrientes con una participación de 14.5 y 34.2\% en 1995 y 2015, respectivamente. El campo de química-metalurgia registra un descenso a lo largo del periodo de 33 a 14.8\%, aunque mantiene un grado de concentración. El patentamiento en el campo de técnicas industriales fue relativamente más estable con participaciones de 20.4 y 19.7\%, entre el inicio y el fin del periodo. Como observamos, al igual que en el caso de los residentes, el patentamiento de los no residentes se concentró prácticamente en los mismos sectores.

En el periodo largo tampoco se notan cambios relevantes en la concentración de la composición si bien se registraron fluctuaciones que revirtieron tendencias. El campo de técnicas industriales diversas y transportes fue el que mostró una tendencia más consistente al mantener a lo largo de los dos periodos una presencia entre $16.5 \%$ en 1940 y $19.7 \%$ en 2015. El campo de necesidades corrientes de la vida muestra cambios entre periodos. Durante la ISI su participación fue decayendo hasta 13.1\% en 1970 respecto del registro en el inicio. Durante el intercambio liberalizado aumenta su presencia a $34.2 \%$ en 2015. El campo de química metalurgia también muestra una inflexión en el patentamiento. A lo largo del régimen proteccionista registra un aumento importante en la participación al alcanzar 37.4\% en 1970, pero para comienzos y durante todo el periodo de intercambio liberalizado este campo declina en participación al registrar 14.8\% en 2015 y prácticamente regresar a niveles inferiores a 1940.

Los campos tecnológicos donde el patentamiento de los no residentes fue más bajo fueron los de construcciones fijas y textiles papel, en ambos periodos. El campo de construcciones fijas alcanzó su tamaño más amplio en 1940 con 8\%. Posteriormente mostró una tendencia descendente en el periodo largo y no se recuperó sino hasta 2015, cuando registró 4.6\% del patentamiento. El campo tecnológico de textiles papel mostró más fluctuaciones, pero también una tendencia descendente en el periodo largo. Durante la ISI llegó a alcanzar 7.1\% de participación en 1940 y 1960 pero desde entonces registró un descenso que fue más pronunciado durante el 
periodo de intercambio liberalizado con sólo $1 \%$ del total de patentes en 2015.

A partir de la comparación del patentamiento durante ambos regímenes económicos, se puede notar que el registro de patentes de los no residentes fue bastante consistente también entre campos tecnológicos. Aunque, por ejemplo, el grado y dirección de los tres campos que más patentes concentraron mostró fluctuaciones, no se observan cambios sustanciales o surgimiento de campos tecnológicos diferentes en el periodo largo dada la perspectiva macroscópica empleada. En cuanto a la relevancia de las tecnologías patentadas por los no residentes, al igual que en el caso de los residentes la falta de información nos impide evaluar la importancia tecnológica o económica de las patentes registradas. En particular las del campo de necesidades corrientes de la vida donde generalmente se ha considerado aglutinan tecnologías tradicionales en alimentos, vestuario, etc., que representan avances técnicos maduros pero que las empresas transnacionales han propendido a patentar de manera importante en el periodo de intercambio liberalizado vigente actualmente, según lo atestiguan algunas de ellas como: Procter \& Gamble, Kimberly Clark, Basf Ak y Novartis, las dos primeras dedicadas a la fabricación de productos para el hogar o bienes de consumo no duradero y las dos últimas a la producción de químicos y medicamentos respectivamente. ${ }^{26}$

\section{CONCLUSIONES}

Las políticas e incentivos establecidos durante la vigencia de cada uno de los dos modelos económicos por los que ha transitado la economía nacional, el proteccionismo y la apertura, comprendieron diferencias importantes que produjeron resultados también distintos. En ambos modelos el expediente tecnológico fue un elemento esencial en la reconfiguración de las estructuras productivas orientadas a las condiciones nuevas de los mercados locales y del exterior. Durante la ISI, aunque se fomentó el desarrollo de la proveeduría local, a la par se incentivó la compra o transferencia de tecnología incorporada y no incorporada del extranjero. Dentro del periodo de intercambio liberalizado se abrieron y se desreglamentaron los mercados incluido el tecnológico, lo que acentuó la dependencia tecnológica del exterior.

${ }^{26}$ Estas empresas son las que han liderado el patentamiento en el país con más de 100 patentes cada una a lo largo del periodo de intercambio liberalizado. Es preciso tener presente también que algunas de ellas como Ciba y Geigy, actualmente fusionadas en Novartis, fueron de las que más patentaron durante la fase final de la ISI. Otras empresas que también han registrado un importante volumen de patentes, aunque con más fluctuaciones, son Janssen Pharmaceutica Nv., Qualcomm Inc., Loreal, S. A., Astra Zeneca PLC, Unilever, Hoechst Ak., Bayer Ak., Hoffman la Roche y Xerox. 
El patentamiento total en México mostró, tanto durante el régimen de la ISI como en el periodo de intercambio liberalizado, un crecimiento alto en la generación o adopción de tecnologías novedosas. Sin embargo, los niveles de actividad fueron bajos al comienzo y durante buena parte de ambos periodos. Se observa también que el desenvolvimiento tecnológico dependió acentuadamente de tecnologías patentadas del extranjero en el periodo largo. Las corporaciones extranjeras mantuvieron el predominio en el patentamiento de los no residentes y progresivamente en el registro total de patentes, y hay un declive paulatino de la participación de innovadores o emprendedores individuales. Se nota que durante la vigencia del periodo de intercambio liberalizado en el caso de los residentes las organizaciones no corporativas han emergido de manera importante, pero no así las de los no residentes. El perfil tecnológico configurado por el registro de patentes de ambos grupos durante los dos periodos muestra que no hubo cambios muy significativos en la dirección de la concentración de las estructuras del desarrollo tecnológico nacional, lo que sugiere una continuidad en la propensión a patentar tanto de los dueños de las patentes de residentes como no residentes.

La continuidad en el patentamiento de casi los mismos campos tecnológicos en ambos periodos conforma un patrón similar de desarrollo tecnológico nacional configurado tanto por residentes como por no residentes al margen de los incentivos establecidos por cada régimen económico o por las políticas de patentes. Teniendo presente la posibilidad de que la perspectiva macroscópica empleada y la categorización tecnológica estandarizada en un nivel muy agregado de los datos estadísticos disponibles pueda dejar de lado matices que confronten los patrones de continuidad del patentamiento, consideramos que la persistencia en la dirección del cambio tecnológico nacional en el periodo largo dentro de entornos cambiantes en la orientación del modelo económico y en cierto modo también de la política de patentes refleja una dependencia de la trayectoria de procesos tecnológicos pasados, la cual no se ha podido reconfigurar o revertir ante incentivos económicos e institucionales diferenciados.

\section{LISTA DE REFERENCIAS}

Aввотt, A. (1997). On the concept of turning point. En L. MJøset, F. Engelstad, G. Brochmann, R. Kalleberg y A. Leira (eds.), Methodological issues in comparative social science (vol. 16, pp. 85-106). Greenwich: JAI Press.

Aвоiтes, J. (1989). Industrialización y desarrollo agrícola en México. México: Universidad Nacional Metropolitana/Plaza \& Valdés. 
Aboites, J. (1995). Cambio institucional e innovación tecnológica. México: Universidad Nacional Metropolitana.

AbOITEs, J. y SORIA, M. (1999). Innovación, propiedad intelectual y estrategias tecnológicas. La experiencia de la economía mexicana. México: Universidad Nacional Metropolitana.

Aboites, J. y Soria, M. (2008). Economía del conocimiento y propiedad intelectual. Lecciones para la economía mexicana. México: Editorial Siglo XXI.

Arapostathis, S. y Gooday, G. (2013). Patently contestable. Electrical technologies and inventor identities on trial in Britain. Cambridge: Massachusetts Institute of Technology.

BAZERMAn, C. (2002). The languages of Edison's light. Cambridge: Massachusetts Institute of Technology.

BEATTy, E. (1996). Invención e innovación: ley de patentes y tecnología en México del siglo XIX. Historia Mexicana, 45(179), 567-619.

BEATTY, E. (2001). Institutions and investment. The political basis of industrialization in Mexico before 1911. Estados Unidos: Stanford University Press.

BEATTY, E. (2002). Patents and technological change in late industrialization: Nineteenth century Mexico in comparative context. History of Technology, 24, 121-150.

BeAtTy, E. (2015). Technology and search for progress in modern Mexico. Estados Unidos: University of California Press.

Beatty, E. y SÁIz, P. (2007). Propiedad industrial, patentes e inversión en tecnología en España y México (1820-1914) (pp. 425-467). En R. Dobado, A. Gómez y G. MÁRQUez (eds.), España y México: ¿historias económicas paralelas? México: Fondo de Cultura Económica.

BÉRTOLA, L. y OCAMPO, J. (2010). Desarrollo, vaivenes y desigualdad. Una historia económica de América Latina desde la independencia. Madrid: Secretaría General Iberoamericana.

Biagioli, M. (2006). Patent republic: Representing inventions, constructing rights and authors. Social Research: An International Quarterly, 73(4), 1129-1172.

BoAs, T. (2007). Conceptualizing continuity and change: The composite-standard model of path dependence. Journal of Theoretical Politics, 19(1), 33-54. DOI: $10.1177 / 0951629807071016$

BOWKer, G. (1994). Science on the run: Information management and industrial geophysics at Schlumberger, 1920-1940. Cambridge: Massachusetts Institute of Technology.

Calderón, C. y SÁnchez, I. (2012). Crecimiento económico y política industrial en México. Revista Problemas del Desarrollo, 43(170), 125-154.

CAmpa, J. (2015). Actividad de patentamiento en el sector educativo superior en México, 1940-1970. Eseconomía, 10(42), 51-79.

Campa, J. (2016). Patentes en México en la época de la Industrialización por Sustitución de Importaciones (Tesis doctoral). Universidad Autónoma de Barcelona, España.

CÁRdenAs, E. (2015). El largo curso de la economía mexicana. De 1780 a nuestros días. México: Fondo de Cultura Económica/El Colegio de México.

Cárdenas, E., Ocampo, J. y Thorp, R. (2003). Industrialización y Estado en la América Latina: la leyenda negra de la posguerra. México: Fondo de Cultura Económica. 
Am. Lat. Hist. Econ., año 25, núm. 3, septiembre-diciembre, 2018, pp. 223-257

Casas, R. y Luna, M. (eds.) (1997). Gobierno, academia y empresas en México. Hacia una nueva configuración de relaciones. México: Plaza y Valdés/Universidad Nacional Autónoma de México.

Castañeda, G. (2010). La evolución de los grupos económicos durante el periodo 1940-2008. En S. Kuntz (ed.), Historia económica general de México: de la colonia a nuestros días (cap. 14). México: El Colegio de México/Secretaría de Economía.

Castro, A., Pacón, A. y Desiderio, M. (2012). Varieties of Latin-American patent offices: Comparative study of practices and procedures. En L. BurLAMAQUI, A. CASTRO y R. KATTEL (eds.), Knowledge governance reasserting the public interest (pp. 165-198). Londres y Nueva York: Anthem Press.

Concha, G. y Calleros, J. (1996). Los caminos de la invención: inventos e inventores en México. México: Instituto Politécnico Nacional.

Corona, L. (2004). La tecnología, siglos XVI al XX. En E. SEmo (coord.), Historia económica de México. México: Universidad Nacional Autónoma de México/Océano.

DAvid, P. A. (1985). Clío and the economics of QWERTY. American Economic Reviere, $75(2), 332-337$.

Fajnzylber, F. (1983). La industrialización trunca de América Latina. México: Nueva Imagen.

GarcíA, A. y Heijx, J. (2012). La política de ciencia y tecnología en México: una síntesis de las etapas, características e instrumentos. En A. IXKIC, M. CABALlero y M. Guerrero (eds.), Retos globales y locales de las ciencias sociales (pp. 117-131). Morelos: Universidad Autónoma del Estado de Morelos.

Gauss, S. (2011). Made in Mexico: Regions, the nation, and the state in the rise of Mexican industrialism, 1920s-1940s. Estados Unidos: Penn State University Press.

Griliches, Z. (1992). Estadísticas de patentes como indicadores económicos: una panorámica. Ekonomiaz. Revista Vasca de Economia, 23(2), 265-320.

Haber, S., Razo, A. y Maurer, N. (2004). The politics of property rights: Political instability, credible commitments, and economic growth in Mexico, 1876-1929. Nueva York: Cambridge University Press.

Instituto Mexicano de la Propiedad Industrial [impi] (1940-1970). Gaceta de la Propiedad Industrial. México: Autor.

Instituto MeXicAno de LA Propiedad Industrial [impi] (2016). IMPI en cifras 2016. México: Autor.

Instituto Nacional de la Investigación Científica (1970). Política nacional y programas en ciencia y tecnología. México: Autor.

Jeannot, F. (2001). Las reformas económicas en México. El desafío de la competitividad. México: Universidad Autónoma Metropolitana/Miguel Ángel Porrúa.

KATZ, J. (1972). Patentes, corporaciones multinacionales y tecnología: un examen crítico de la legislación internacional. Desarrollo Económico, 12(45), 142-143.

KATZ, J. (1980). Importación de tecnología, aprendizaje e industrialización dependiente. México: Fondo de Cultura Económica. 
Kuntz, S. (coord.) (2010). Historia económica general de México: de la colonia a nuestros días. México: El Colegio de México/Secretaría de Economía.

Ley de Fomento y Protección de la Propiedad Industrial (27 de junio de 1991). Diario Oficial de la Federación.

Lomnitz, L. y Pérez-Lizaur, M. (1987). A Mexican elite family, 1820-1980. Princeton: Princeton University Press.

MaríA y CAMPOS, M. (1968). Transferencia de tecnología: dependencia exterior y desarrollo económico (Tesis de licenciatura). Universidad Nacional Autónoma de México, México.

Márquez, G. (coord.) (2014). Claves de la historia económica de México. El desempeño de largo plazo (siglos XVI-XXI). México: Fondo de Cultura Económica/CONACULTA.

Martínez, J. (coord.) (2008). Generación y protección del conocimiento: propiedad intelectual, innovación y desarrollo económico. México: Comisión Económica para América Latina y el Caribe.

Mazzoleni, R. y Nelson, R. (1998). The benefits and costs of strong patent protection: A contribution to the current debate. Research Policy, 27(3), 273-284. DOI: 10.1016/ S0048-7333(98)00048-1

Mercado, A. (1986). Desarrollo y crisis de la capacidad tecnológica latinoamericana. El caso de la industria metalmecánica. Argentina: Banco Interamericano de Desarrollo/Comisión Económica para América Latina y el Caribe.

Mercado, A. y Lombó, L. (1982). Un estudio sobre el cambio tecnológico de una empresa mexicana productora de máquinas para molinos. Programa de investigación sobre desarrollo científico y tecnológico en América Latina (Monografía de trabajo, núm. 54). Argentina: Banco Interamericano de Desarrollo/Comisión Económica para América Latina y el Caribe.

Moreno-Brid, J. y Ros, J. (2009). Development and growth in the Mexican economy: A historical perspective. Oxford: Oxford University Press.

Oficina EsPañola de Patentes y MaRCAs [OEPM]. (2006). Clasificación internacional de patentes. Recuperado de http://cip.oepm.es/descargas/20060101 [Consulta: 10 de febrero de 2017.]

ORganización DE LAS NACIONES Unidas [ONU] (1964). La función del sistema de patentes en la transmisión de tecnología a los países en desarrollo. Nueva York: Autor.

ORGANIZACIÓN DE LAS NACIONES UNIDAS [ONU] (1975). La función del sistema de patentes en la transmisión de tecnología a los países en desarrollo. Nueva York: Autor.

Organización Mundial de la Propiedad Intelectual. Oficina de Publicaciones (1983). Industrial property statistics. Génova: Autor.

ORgANiZACIÓN PARA LA COOPERACIÓN Y EL DESARROllo ECONÓMICOS [OCDE] (2009). Manual de estadísticas de patentes de la OCDE. Francia y España: Foro Consultivo y la Oficina Española de Patentes y Marcas.

Padua, J. (1984). Educación, industrialización y progreso técnico en México. Un estudio de caso en la zona conurbada de la desembocadura del río Balsas. México: El Colegio de México/Unesco.

Penrose, E. (1974). La economía del sistema internacional de patentes. México: Siglo XXI. 
Am. Lat. Hist. Econ., año 25, núm. 3, septiembre-diciembre, 2018, pp. 223-257

Pérez, C. (1996). La modernización industrial en América Latina y la herencia de la sustitución de importaciones. Comercio Exterior, 46(5), 347-363.

PÉrez-Lizaur, M. (1996). El empresario tecnológicamente innovador y su contexto. Nueva Antropología, 15(50), 127-146.

Rossi, F. (1977). El empresario mexicano. México: Universidad Nacional Autónoma de México.

SÁIz, J. (1996). Legislación histórica sobre propiedad industrial. España (1759-1929). Madrid: Oficina Española de Patentes y Marcas.

SÁIz, J., (2002). The Spanish patent system (1770-1907). History of Technology, 24, 45-79.

Science And Technology Policy Instruments (1980). Ciencia y tecnología para el desarrollo: informe comparativo central del proyecto STPI. Bogotá: Francisco Sagasti.

SECretaría de Relaciones Exteriores. Dirección General de Inversión Extranjera (2016). Inversión extranjera directa en México y en el mundo. Carpeta de información estadística. México: Autor.

Sepúlveda, B. y Chumacero, A. (1973). La inversión extranjera en México. México: Fondo de Cultura Económica.

Shadlen, K. (2010). The puzzling politics of patents and innovation policy in Mexico. Law and Business Review of the Americas, 16(4), 823-838.

Shadlen, K. (2012). The Mexican exception: Patents and innovation policy in a nonconformist and reluctant middle income country. European Journal of Development Research, 24, 300-318.

Tornell, A. (2002). Economic crises and reform in México. En S. Haber (ed.), Crony capitalism and economic growth in Latin America: theory and evidence (cap. 5). California: Stanford University.

VAitsos, C. (1972). Patents revisited: Their function in developing countries. Journal of Development Studies, 9(1), 71-97. DOI: 10.1080/00220387208421432

Vergne, J-P. y Durand, R. (2010). The missing link between the theory and empirics of path dependence: Conceptual clarification, testability issue, and methodological implications. Journal of Management Studies, 47(4), 736-759. DOI: 10.1111/j.1467-6486.2009.00913.x

WionczeK, M. (1981). Capital y tecnología en México y América Latina. México: Miguel Ángel Porrúa.

Wionczek, M., Bueno, G. y Navarrete, J. (1988). La transferencia internacional de tecnología: el caso de México. México: Fondo de Cultura Económica.

\section{OTRAS FUENTES}

\section{Bibliografía}

Maddison, A. (1995). Monitoring the world economy, 1820-1992. Washington, D. C.: Organization for Economic Cooperation and Development. 